
Egyptian Journal of
Egy. J. Phys. Ther. Jun 2021; 6:1-8
Original article
Physical
Therapy $(\mathrm{EJPT})$
https://ejpt.journals.ekb.eg

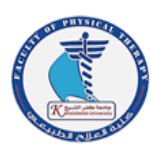

\title{
Prevalence of football injuries in Egyptian children and adolescents and its correlation to anthropometric parameters
}

\author{
Reham E. mohammed ${ }^{1}$, Bassem G. Elnahass ${ }^{1}$, Mona M. Ibrahim¹
}

1 Orthopedic Department, Faculty of Physical Therapy, Cairo University, Egypt

\author{
*Correspondence to \\ Reham E. Mohammed, \\ Department of orthopedic, \\ Faculty of Physical Therapy, \\ Cairo University, Cairo, \\ Egypt. \\ Tel:01000917788 \\ Email: \\ rorohy2017@yahoo.com
}

\section{Published online:}

Jun 2021

\begin{abstract}
Purpose the study aims to survey the prevalence and incidence of football injuries at the age group from (10-15) years old to correlate the injuries to anthropometric measurements as body and the height and correlate injuries to the player's position in the field.

Methods 100 players were randomly selected their history of injuries and their positions were recorded and 12 measurements (weight, height, sitting height, lower extremity length, thigh length, arm length, head, waist, upper arm, thigh and calf circumferences and BMI were calculated.

Results $23 \%$ players had been injured for only one injury within the recorded two seasons, $12 \%$ players and $5 \%$ players had been injured for two times and three times, respectively. with incidence $32 \%$ and prevalence $21 \%$. Spearman's rho correlation was tested between the player position and injury both recent and previous. A moderate positive correlation (0.3-0.7) was found between the player position and both total and recent injuries with no significant correlation between the player position and their previous injuries. No significant correlation between the anthropometric measurements and injuries.

Conclusion players at (10-15) years old are highly suspected for injuries especially fractures, most of those injuries are contact injuries which occurs during the match. Anthropometric measurements cannot be used to predict the incidence of injuries. Defenders were the highly suspected for injuries.

Key words: football, childhood, adolescence, injuries, anthropometry
\end{abstract}

\section{Introduction}

Football is the most popular sport all over the world for any age especially children and youth as 265 million persons play it. football is characterized by highly intensive movements with short breaks over different periods of times during the matches which put the player in a high risk of injury (1). The injuries considered to be 0.5 to 5.6 injury per 1000 hour matches. Those injuries affect the player performance, which lead to missing several training sessions and matches. Furthermore, it may affect the process of growing when it occurs at early age especially those which require surgical intervention and long period of rehabilitation (2). Football injuries may be traumatic that occur suddenly which usually seen at the match. On the other hand, it may be overuse injury caused by training or playing for a long period without or with minimal periods of rest. It was suggested that overuse injuries are more likely to be linked with early childhood injuries (1). The most common risk factors of football injuries are A) extrinsic factors that include 
lack of protective equipment, rules, and regulation, playing surface character, and pressure from parents and B) Intrinsic factors that may be non-modifiable, such as sex, personality, age, skeletal maturity, or previous injury, or modifiable by prevention like muscle strength, joint stability, social factors, coping strategies, fitness level, coordination, and psychological factors $(3,4)$.

Another common factors that considered to contribute the occurrence of injury is the anthropometric characteristic or the physical status of the player, body mass, height, BMI, and different circumference of the body (5). Furthermore, these characteristics provide some information about the player position for example A) mid-field players tend to be lighter to move through the space more efficiently and cover more distances in running, B) goalkeepers tend to be with long upper extremities and heavier to allow them reaching the ball to high extent, c) Defenders tend to be heavier and taller with less body fat, as their position requires them to be robust and strong in the tackle, and D) attackers, their body is of a different length $(5,6)$.The coach integrates those physical characteristic with the players skills to put the player in the best position $(5,6,7)$.

Studies that are concerned with young age and children injuries and its relation to different anthropometric characteristics are limited in addition to that each study differ in its definition of injury. However, to provide a safe future for the young players there was a necessity to know the incidence and nature of injuries and their relation to anthropometric characteristics to control it. (7)

The current study aims to.

1 - find the prevalence rate of football injuries within the players from (10-15) years old.

2- find the incidence of football injuries within the player from (10-15) years old.

3- find a correlation between the player's anthropometric variables and player injuries and their position in the field.

\section{Patients and Methods}

2.1. This is a cross-sectional study which was conducted in accordance with the guidelines and approved by the local Ethics committee of the Faculty of Physical Therapy, Cairo University, Egypt.

Participants:

Hundred (100) male football players were recruited from two football clubs within Cairo city. Their ages ranged from (10-15) years' old.

Coaches, parents, and the participant's players were informed by the study, its purpose, and procedures. the study started in (1-1-2020) and ended in (10-4-2020) 2.2. Procedures:

2.2.1. Firstly, General information were collected from A) the coaches about the period of season, number of matches per week, number or training hours per week, periods of rest during season and the type of playing ground.

And from B) the participants about any injury related to football playing that occurred in the current season within the following period (1-8-2019:31-3-2020) or in the last season within the following period (1-82018: 30-4-2019), if there was an injury information's about its site, timing and period of treatment were collected.

2.2.2. Secondly, an anthropometric measurement was taken for all participants for the following parameters:

1 - body weight

2-standing length

3-sitting length

4-upper arm length

5-lower extremity length

6-thigh length

7-BMI

8-head circumference

9-waist circumference

10-upper arm circumference

11-thigh circumference

12-calf circumference

Every measure was taken three times and the average was calculated.

1.Body weight was measured by a digital (PROmed) scale the player took off his shoes and stand erect on the scale, his eyes forwards (8)

Selected lengths: these lengths were measured by traditional tape.

2. standing height: the participant stood against a standardized tape fixed on a wall and a horizontal piece placed on the top of participant's head and the measure recorded (9)

3. sitting height: the player sits on a chair with his back erect and his arms asides, measurements were taken by a traditional tape from the lower point of the back to the top of the head (8)

4. arm length: the distance between the end of the spine of the scapula to the posterior aspect of the elbow was measured (10)

5. lower extremity length: the distance from anterior superior iliac spine to the floor during standing with shoes off. (11).

6. thigh length: the participant was asked to sit on chair with knees 90 flexed, the examiner identify the tip of patella on anterior thigh, then asked the participant to stood up and measure the distance up to inguinal creases (10).

The selected circumferences were measured by a traditional tape in the following way:

7. Head circumference: the rounded measure from the frontal bone above eyes brows to the protuberance of the skull was recorded, the tape was moved above and down then the largest rounded measurement was taken 
(10).

8. waist circumference: the examiner took a point midway between lower ribs and the hip bone with the participant standing then asked him to take his breath out gently the tape was put around and the measurement recorded (10).

9. upper arm circumference: the round measurement midway between the end of the spine of the scapula and the posterior aspect of the elbow was recorded (10).

10. thigh circumference: measured by a tape not loose nor tight midway between inguinal creases and the patellar tip from standing position (11).

11.calf circumference: the tape was placed around the calf not too tight nor too loose and was moved along the length of the calf to obtain the maximal circumference (12).

Finally, the body mass index (BMI) was calculated BMI $=\mathrm{kg} / \mathrm{m} 2$ where $\mathrm{kg}$ is a person's weight in kilograms and $\mathrm{m} 2$ is their height in meters squared (13) 2.3. Statistical analysis

- Statistical analysis was performed using IBM SPSS statistics version 20 (SPSS Inc., Chicago, IL, USA).

- Quantitative variables will be presented in terms of means, SD

- Significance will be set at 0.05 .

\section{Results}

This study was done on 100 football players within the age of (10-15) years old. The study surveys their injuries related to football playing within two seasons the first from (1-8-2018; 30-4-2019) and injury here considered to be pervious injury, the second one from (1-8-2019: 31-3-2020) and the injury here considered to be recent injury, in addition to that the study measured 12 anthropometric parameters and check if there is correlation between the injuries and parameters or not considering the player's position in the ground. The frequency distribution of the payers according to their age and time of injures are illustrated in table 1 and 2 .

Table 1: Frequency distribution of players according to their age

\begin{tabular}{ccc}
\hline & Frequency & Percent \\
\hline $\mathbf{1 0}$ & 8 & $8 \%$ \\
$\mathbf{1 1}$ & 14 & $14 \%$ \\
$\mathbf{1 2}$ & 18 & $18 \%$ \\
$\mathbf{1 3}$ & 21 & $21 \%$ \\
$\mathbf{1 4}$ & 19 & $19 \%$ \\
$\mathbf{1 5}$ & 20 & $20 \%$ \\
Total & 100 & $100 \%$ \\
\hline
\end{tabular}

23 players had been injured for only one injury within the recorded two seasons. Furthermore, 12 players and
5 players had been injured for two times and three times respectively, within the recorded time. The number of injuries and their percentage were illustrated in table 2

Table 2: number of total injuries (recent \&pervious) within the players

\begin{tabular}{llll}
\hline & & Frequency & Percent \\
\hline & $\begin{array}{l}\text { 1(one } \\
\text { injury) } \\
\text { 2(twice } \\
\text { injury) }\end{array}$ & 23 & $23 \%$ \\
Total & 12 & $12 \%$ \\
injuries & $\begin{array}{l}3 \text { (triple } \\
\text { injury) }\end{array}$ & 5 & $5 \%$ \\
& $\begin{array}{c}\text { Total } \\
\text { 0 }\end{array}$ & 60 & $40 \%$ \\
& Total & 100 & $60 \%$ \\
\hline
\end{tabular}

The incidence of recent injury in the reported season was found to be $32 \%$ in which 27 players were injured once and five players were injured twice as shown in table 3

Table 3: number and percentage of recent injuries

\begin{tabular}{llll}
\hline & & Frequency & Percent \\
\hline $\begin{array}{l}\text { Recent } \\
\text { injury }\end{array}$ & $\begin{array}{l}\text { injury) } \\
\text { 2(twice } \\
\text { injury) } \\
\text { Total }\end{array}$ & 5 & $27 \%$ \\
& 0 & 68 & $5 \%$ \\
& Total & 100.0 & $\mathbf{3 2 \%}$ \\
\hline
\end{tabular}

The prevalence of injury in the previous season was found to be $21 \%$ in which 17 players was injured once and 4 players were injured twice as shown in table 4.

Table 4: number and percentage of pervious injuries 


\begin{tabular}{cccc}
\hline & $\begin{array}{c}\text { 1(one } \\
\text { injury) }\end{array}$ & 17 & $\mathbf{1 7 \%}$ \\
& $\begin{array}{c}\text { 2(twice } \\
\text { Pervious } \\
\text { injury }\end{array}$ & 4 & $\mathbf{4 \%}$ \\
& Total & 21 & $\mathbf{2 1 \%}$ \\
& 0 & 79 & $\mathbf{7 9 \%}$ \\
& Total & 100 & $\mathbf{1 0 0 \%}$ \\
\hline
\end{tabular}

Spearman's rho correlation was tested between the player position and injury both recent and previous as shown in table 5. A moderate positive correlation (0.30.7) was found between the player position and both total and recent injuries with no significant correlation between the player position and their previous injuries. No significant correlations were found between BMI and both recent and previous injures as illustrated in table 6. Moreover, no significant correlated were found between measured anthropometric measures and both recent and previous injures as shown in table 6 .

No significant correlation between the anthropometric measurements and injuries as shown in table 7.

some players have a recent fracture (humeral head fracture, metatarsal bone fracture and lower forearm fractures), others have a recent strain injury (quadriceps contusion and adductors strain) and another player have recent sprain injury (lateral ankle ligaments sprain). table 8 shows 16 players have a recent fracture, 8 players have a recent strain injury, and 3 players have a recent sprain injury.

Table8: number of recent injuries according to the type of injury

\begin{tabular}{ccc}
\hline & Frequency & Percent \\
\hline $\mathbf{1}$ (fractures) & 16 & $16 \%$ \\
$\mathbf{2}$ (strain injury) & 8 & $8 \%$ \\
$\mathbf{3}$ (sprain injury) & 8 & $8 \%$ \\
Total & 32 & $32 \%$ \\
0 & 68 & $68 \%$ \\
Total & 100 & $100 \%$
\end{tabular}

Some players have pervious fracture (humeral head fracture, tibial fracture, forearm fracture and tarsal bone fracture), others have pervious strain injury (hamstrings strain and adductor strain), and another have pervious sprain injury (lateral collateral ligaments sprain and knee ligaments sprain).

table 9 shows 8 players have pervious fracture), 6 players have pervious strain injury, and 7 players have pervious sprain injury.

Table 9: number of pervious injuries according to the type of injury

\begin{tabular}{ccc}
\hline & Frequency & Percent \\
\hline 1(fractures) & 8 & $8 \%$ \\
2(strain injury) & 6 & $6 \%$ \\
3(sprain injury) & 7 & $7 \%$ \\
Total & 21 & $21 \%$ \\
$\mathbf{0}$ & 79 & $79 \%$ \\
Total & 100 & $100 \%$ \\
\hline
\end{tabular}

\section{Discussion}

The study mainly aims to record and survey the number of football sport injuries within the childhood and adolescent period specially from (10-15 years old). The injury was defined in the current study as footballrelated trauma or overload that led to pain and/or dysfunction that in turn prevent the child or the adolescent from participating in training or matches during at least one week, thus being time-loss injuries (14).

The study survey randomly 100 players from two different club inside Cairo city. The players were selected by the coaches from different teams. it was intended to recruit a greater number of players, but it was too hard in accordance with quatrain to avoid COVID-19 infection.

Totally from the 100 players $40 \%$ were injured, $23 \%$ injured only once, $12 \%$ developed twice injury and 5\% developed a third one. Out of the $40 \%$, (23\% were recent injuries and $21 \%$ were pervious injuries).

The injury types differ among the participants as $16 \%$ of the developed recent and $8 \%$ of the pervious injuries were fractures in the humeral head, forearm, and foot tarsal bone. This type of injury occurred as a contact injury during the match, considering the impulsive behavior of the participant and their willingness to win. The second common injury were muscles strain as $8 \%$ of the recent injuries and 6\%of the pervious injuries were quadriceps contusion. 
Table 5 Correlation between the player position and the injuries

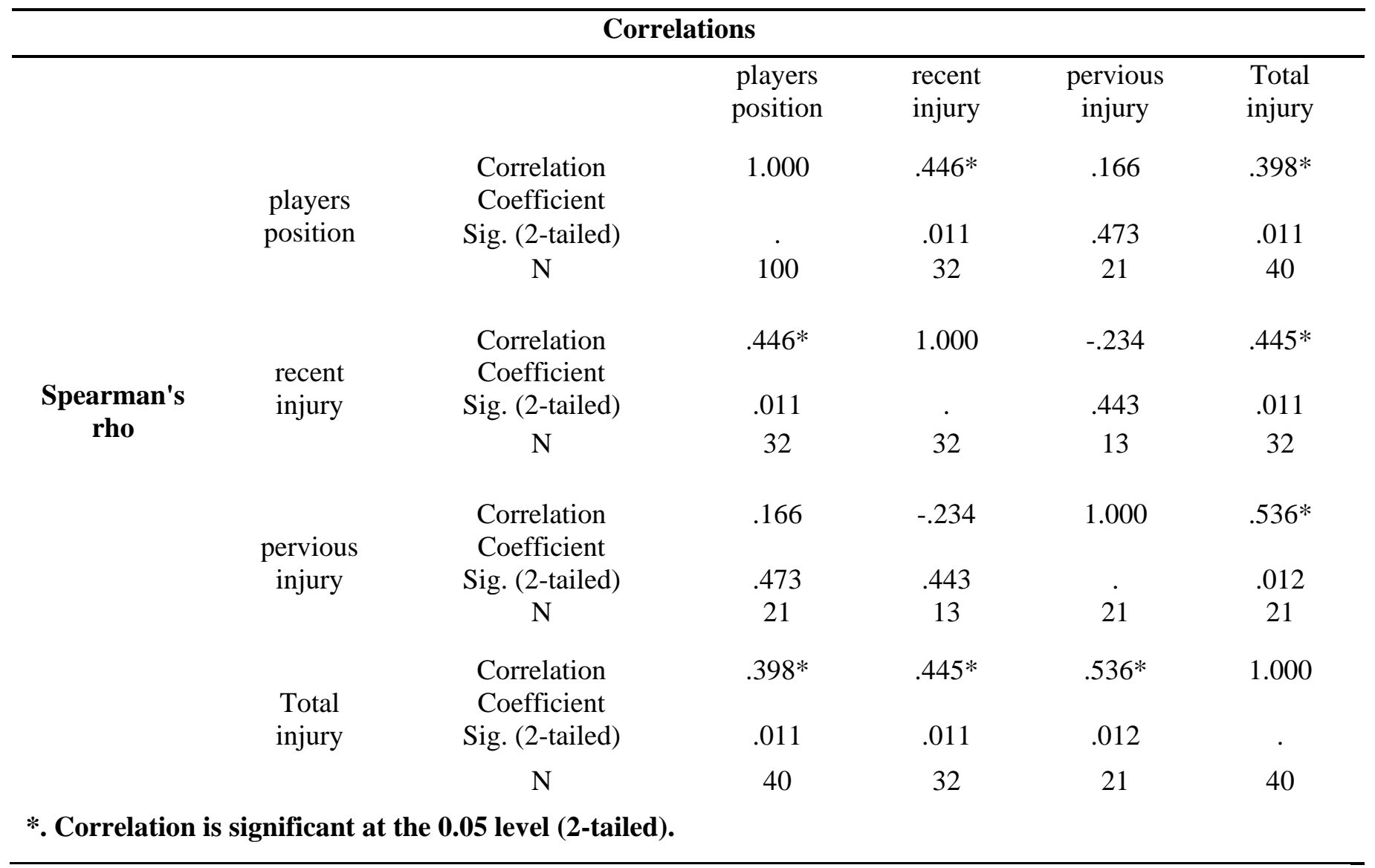

Table 6: BMI correlation with the injuries

\section{Correlations}

\begin{tabular}{|c|c|c|c|c|c|c|}
\hline & & & BMI & $\begin{array}{l}\text { recent } \\
\text { injury }\end{array}$ & $\begin{array}{l}\text { pervious } \\
\text { injury }\end{array}$ & $\begin{array}{l}\text { Total } \\
\text { injury }\end{array}$ \\
\hline & & Correlation & 1.000 & -.145 & -.101 & -.106 \\
\hline & BMI & Coefficient & & & & \\
\hline & & Sig. (2-tailed) & . & .428 & .665 & .514 \\
\hline & & $\mathrm{N}$ & 99 & 32 & 21 & 40 \\
\hline & & Correlation & -.145 & 1.000 & -.234 & $.445^{*}$ \\
\hline & recent & Coefficient & & & & \\
\hline Spearman's & injury & Sig. (2-tailed) & .428 & . & .443 & .011 \\
\hline rho & & $\mathrm{N}$ & 32 & 32 & 13 & 32 \\
\hline & & Correlation & -.101 & -.234 & 1.000 & $.536^{*}$ \\
\hline & pervious & Coefficient & & & & \\
\hline & injury & Sig. (2-tailed) & .665 & 443 & & .012 \\
\hline & & $\mathrm{N}$ & 21 & 13 & 21 & 21 \\
\hline & & Correlation & -.106 & $.445^{*}$ & $.536^{*}$ & 1.000 \\
\hline & Total injury & Coefficient & & & & \\
\hline & & Sig. (L-tanled) & .514 & .011 & .012 & in \\
\hline & & $\mathrm{N}$ & 40 & 32 & 21 & 40 \\
\hline
\end{tabular}

*. Correlation is significant at the 0.05 level (2-tailed). 
Table7: Anthropometric parameters correlation with the injuries

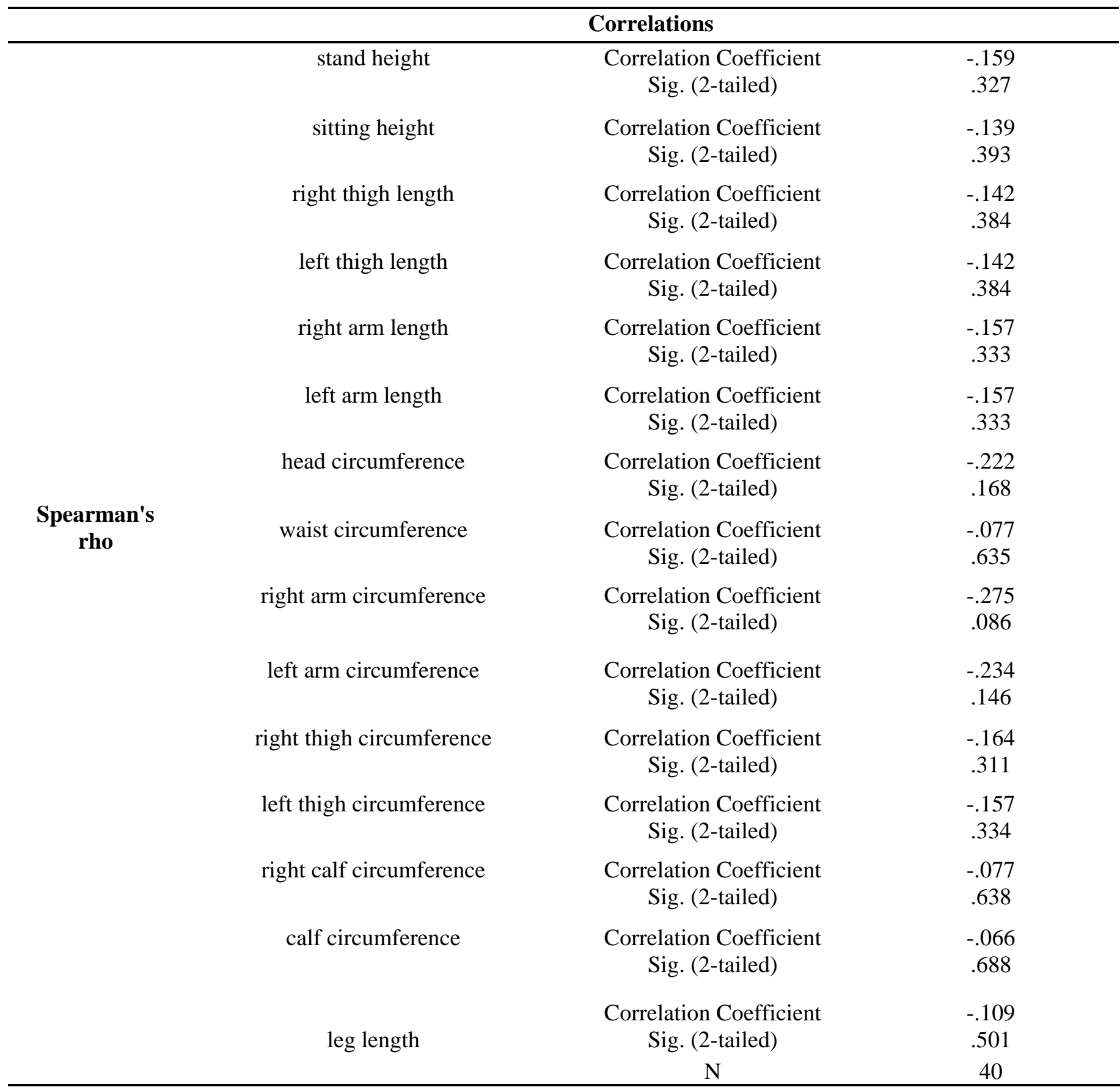

which occurred as direct contact injury in the match. Hamstrings and adductors strain sometimes occurred during the match with the over running and others were developed as overstretch excessing during the training sessions.

In the third-place sprain injuries developing as $8 \%$ of the recent injuries and $7 \%$ of the pervious injuries were in form of ankle ligament sprain that developed during running and fighting on the ball.

Possible explanation for the frequent fractures at the early age may be skeletal immaturity and incomplete coordination $(15,16)$
The study results hard to be compared with other studies as this type of studies varied according to several factors as definition of injury, the period of the study, the nation of the players and the different physical shape, but it similar to number of studies which concluded that fracture injuries are more frequent in this age $(15,16,17)$ also some studies agreed that most of injuries in this age are contact ,collision injuries which occurred in the match not in the training times $(18,19,20,21,22)$

From the screening for five different player's positions in this study (defenders, attackers, 
goalkeepers, mid field, and the strikers).it was observed more incidence of injury within the defenders followed by attackers and goalkeepers and the least incidence within the stickers and mid field players. As mentioned before the fractures still the most frequent injury followed by strains and sprains. The anthropometric measurements that was measured in this study show that there were no significant correlations with the recorded injuries, it was suggested that the absence of correlation was due to the limited sample size as a number of studies suggest that there was a correlation between higher BMI and increased the risk of injury $(9,23,24,25,26)$, according to another study lower extremity circumference was considered as risk factor for football injury as high thigh circumference increase risk of injury epically if the calf circumference was low (27)

the study results were like some studies which also did not show a correlation between the parameters and the injury $(8,28)$. But others suggested that combination between anthropometric parameters as height and body weight with movement screening tests might be associated with increased lower limb risk of injury $(29,30)$.

\section{Conclusion}

players at (10-15) years old are highly suspected for injuries especially fractures, most of those injuries are contact injuries which occurs during the match. Anthropometric measurements cannot be used to predict the incidence of injuries. Defenders were the highly suspected for injuries.

\section{Acknowledgments}

For the cooperative coaches of the involved clubs.

\section{Conflict of Interest}

The authors declare no conflict of interest.

\section{References}

1. Faude, O., Rößler, R., \& Junge, A. Football injuries in children and adolescent players: are there clues for prevention? Sports medicine.2013 May 43(9), 819-837.

2. Junge, A., \& Dvorak, J. Influence of definition and data collection on the incidence of injuries in football. The American Journal of Sports Medicine.2000 Sep 28(5), 40-46.

3. Woods, C. T., Raynor, A. J., Bruce, L., McDonald, Z., \& Collier, N. Predicting playing status in junior Australian Football using physical and anthropometric parameters. Journal of Science and Medicine in Sport.2015 March 18(2), 225-229.
4. Corluka, M., Bjelica, D., Vasiljevic, I., Bubanja, M., Georgiev, G., \& Zeljko, I. Differences in the morphological characteristics and body composition of football players of hsc zrinjski mostar and fc siroki brijeg in bosnia and herzegovina. Sport Mont.2018 March 16(2), 7781.

5. Hencken, C., \& White, C. Anthropometric assessment of Premiership soccer players in relation to playing position. European Journal of Sport Science.2006 Dec 6(4), 205-211.

6. Erdmann, W. S. Application of biomechanics in soccer training. In Routledge Handbook of Biomechanics and Human Movement Science 2008 (pp.537-549) Routledge.

7. Price, R. J., Hawkins, R. D., Hulse, M. A., \& Hodson, A. The Football Association medical research programme: an audit of injuries in academy youth football. British journal of sports medicine.2004 May 38(4), 466-471.

8. Caswell, S. V., Ausborn, A., Diao, G., Johnson, D. C., Johnson, T. S., Atkins, R., ... \& Cortes, N Anthropometrics, physical performance, and injury characteristics of youth American football. Orthopaedic journal of sports medicine 2016 4(8), 2325967116662251.

9. Kemper, G. L. J., Van Der Sluis, A., Brink, M. S., Visscher, C., Frencken, W. G. P., \&ElferinkGemser, M. T. Anthropometric injury risk factors in elite-standard youth soccer. International journal of sports medicine.2015 May 36(13), 1112-1117.

10. Centers for Disease Control and Prevention. Anthropometry procedures manual. National Health and Nutrition Examinatory Survey (NHANES).2007 Jan, 102.

11. Morina, B., Tahiraj, E. N., Bahtiri, A., Elezi, A., \&Hadzic, R. Comparative analysis of anthropometric body dimensions between primary school students from Kosovo and Montenegro, in relation to their age. International Journal of Applied Exercise Physiology.2018 Jul 7(4), 41-49.

12. Orhan, Ö., Sagir, M., \& Zorba, E. Comparison of somatotype values of football players in two professional league football teams according to the positions. Collegium antropologicum.2013 Feb 37(2), 401-405.

13. Neyzi, O., Bundak, R., Gökçay, G., Günöz, H., Furman, A., Darendeliler, F., \&Baş, F. Reference values for weight, height, head circumference, and body mass index in Turkish children. Journal of clinical research in pediatric endocrinology.2015 Dec 7(4), 280.

14. Boström, A., Thulin, K., Fredriksson, M., Reese, D., Rockborn, P., \&Hammar, M. L. Risk factors for acute and overuse sport injuriesinSwedishchildren11to15yearsold: 
Whataboutresistancetraining with weights? Scandinavian journal of medicine \& science in sports.2016 Feb 26(3), 317-323.

15. Dahlström, Ö., Backe, S., Ekberg, J., Janson, S., \& Timpka, T. Is "football for all" safe for all? Crosssectional study of disparities as determinants of 1year injury prevalence in youth football programs. PloS one.2012 Aug 7(8), e43795.

16. Turbeville, S. D., Cowan, L. D., Asal, N. R., Owen, W. L., \& Anderson, M. A. Risk factors for injury in middle school football players. The American journal of sports medicine.2003 March 31(2), 276281.

17. Amirshaghaghi, F., Pournemati, P., \& Zandi, S. Does body composition play a role in predicting sports injuries? A systematic review. journal of exercise science and medicine.2019 Sep 11(2).

18. Sugimoto, D., Howell, D. R., Tocci, N. X., \& Meehan III, W. P. Risk factors associated with selfreported injury history in female youth soccer players. The Physician and sportsmedicine.2018 April 46(3), 312-318.

19. Putra, M. P., Kristiyanto, A., \& Rachma, N. Correlation of Physical Conditions and Anthropometric Factors for the Risk of Sports Injuries. Journal of Education, Health and Sport.2019 April 9(4), 513-519.

20. Goldberg, B., Rosenthal, P. P., Robertson, L. S., \& Nicholas, J. A. Injuries in youth football. Pediatrics.1988 Feb 81(2), 255-261.

21. Stuart, M. J., Morrey, M. A., Smith, A. M., Meis, J. K., \& Ortiguera, C. J. Injuries in youth football: a prospective observational cohort analysis among players aged 9 to 13 years. In Mayo Clinic Proceedings.2020 April 77(4), 317-322).

22. Frisch, A., Croisier, J. L., Urhausen, A., Seil, R., \&Theisen, D. Injuries, risk factors and prevention initiatives in youth sport. British med bulletin.2009 Sep 92(1),95-121.

23. Dompier, T. P., Kerr, Z. Y., Marshall, S. W., Hainline, B., Snook, E. M., Hayden, R., \& Simon, J. E. Incidence of concussion during practice and games in youth, high school, and collegiate American football players. JAMA pediatrics.2015 Jul 169(7), 659-665.

24. Emery, C. A., Meeuwisse, W. H., \& Hartmann, S. E. Evaluation of risk factors for injury in adolescent soccer: implementation and validation of an injury surveillance system. The American journal of sports medicine.2005 Dec 33(12), 18821891

25. Ghigiarelli, J. J. (2011). Combine performance descriptors and predictors of recruit ranking for the top high school football recruits from 2001 to 2009: Differences between position groups. The
Journal of Strength \& Conditioning Research.2011 May 25(5), 1193-1203.

26. Rössler, R., Junge, A., Chomiak, J., Němec, K., Dvorak, J., Lichtenstein, E., \& Faude, O. Risk factors for football injuries in young players aged 7 to 12 years. Scandinavian journal of medicine \& science in sports.2018 Sep 28(3), 1176-1182.

27. Onate, J. A., Dewey, T., Kollock, R. O., Thomas, K. S., Van Lunen, B. L., DeMaio, M., \& Ringleb, S. I. Real-time intersession and interrater reliability of the functional movement screen. The Journal of Strength \& Conditioning Research.2012 Feb 26(2), 408-415.

28. Williams, A. M., \& Reilly, T. Talent identification and development in soccer. Journal of sports sciences .2000 Feb 18(9), 657-667.

29. Leão, C., Camões, M., Clemente, F. M., Nikolaidis, P. T., Lima, R., Bezerra, P., ... \& Knechtle, B. Anthropometric profile of soccer players as a determinant of position specificity and methodological issues of body composition estimation. International journal of environmental research and public health.2019 Dec 16(13), 2386.

30. Nikolaidis, P. T., \& Karydis, N. V. Physique and body composition in soccer players across adolescence. Asian journal of sports 